\title{
Social and Cultural Factors in Women's Health in Rural Africa
}

\author{
Bethany A. Murray, PhD, RN \\ Indiana University School of Medicine. Bloomington, Indiana, U.S.A \\ *Corresponding Author: Indiana University School of Medicine. Bloomington, Indiana, U.S.A \\ Received Date: 01-07-2017 \\ Accepted Date: 06-07-2017 \\ Published Date: 10-07-2017

\begin{abstract}
The purpose of this study was to examine sociocultural factors that impact self-care and health maintenance of women in The Kingdom of Swaziland and to develop a deeper understanding of how cultural values are a determinant of health outcomes. Data was ethnographic and narrative in nature. Carspecken's process of critical ethnography was used to structure the study and for analysis of the data. Findings were then applied to the culturally sensitive Person-Environment-Neighborhood (PEN-3) model. The findings illustrate how social issues such as poverty and food insecurity dramatically impact the health of Swazi women and children. Traditional customs both support and threaten health. Application of the PEN-3 model targeted areas of intervention and identified the community as the appropriate level of entry.
\end{abstract} \\ Keywords: Women's Health, Sociocultural, Critical Ethnography, PEN-3
}

\section{INTRODUCTION}

The Kingdom of Swaziland (SZ) is located in the sub-Saharan region of the continent of Africa. SZ is approximately $17,000 \mathrm{~km}^{2}$ in size with a population of over 1.2 million people (World Health Organization [WHO], 2014). Swazi citizens are predominantly young: Only $5.3 \%$ of Swazi citizens are over the age of 60years and one-third of the country is under the age of 15-years (Global Health Observatory [GHO], 2014). Swaziland gained full independence from Great Britain in 1968 and is relatively homogeneous as a nation with a single ethnic heritage (the Ngwane, or Swazi) comprised of many tribal affiliations and one local language (siSwati) (Matsebula, 1988). SZ is administered collaboratively as both a monarchy and a democratically elected government. King Mswati III is the current ruler of the country aided by his mother, Queen Ntfombi. Historically, Queen mothers have held an important role serving as national Regent when a King is of minor age or has yet to be selected. Swaziland's dual political system incorporates both traditional institutions and customs and westernized methods of modern governance administered under the Constitution of Swaziland (The Government of the Kingdom of Swaziland, 2014). This mode of governance complicates many aspects of Swazi life; for example, marriage rules may be enacted either under customary law, under the Marriage Act of 1964, or under both. These laws may be in conflict or interpreted differently at a local level (Bhalla, 2000).

King Mswati III owns approximately $60 \%$ of all of the land of SZ and he manages it through 360 appointed tribal chiefs. Marriage, child custody, property rights and inheritance laws remain largely covered by traditional custom; which, strongly reflect patriarchal norms and practices including polygyny, lobola (bridewealth), and unkungena, or wife inheritance (Gardsbane \& Hlatshwayo, 2012).

Swaziland is chiefly an agricultural country. Its main exports are sugar, cotton and wood pulp. 
$79 \%$ of Swaziland citizens live in a rural setting and rely on subsistence farming (GHO, 2014). Rural people tend to live in multi-family homesteads that are widely scattered, leading to problems with the location of schools, health clinics and other governmental services (Connolly \& Dunn, 1986). Rural roads are unpaved, and many citizens must walk long distances to access public bus stops.

\section{Health Outcomes}

SZ has seen dramatic increases in negative disease outcomes and early death. Men and women have an average life expectancy of 52years and 55-years respectively (WHO, 2014). SZ has the highest HIV prevalence rate of any country in the world: $27.4 \%$ of all adults aged 15-49 years and 39\% of pregnant women aged 15-24 years are HIV-positive (GHO, 2014). Complications related to AIDS and opportunistic tuberculosis (TB) infections account for onethird of all hospital deaths and the incidence of these infections is increasing (GHO, 2014; Ministry of Health $[\mathrm{MOH}], 2010)$. In areas of women's health, maternal mortality remains high, cervical cancer is the $17^{\text {th }}$ leading cause of death for women, and surgery was still the only treatment option for women with breast cancer in 2013 (All Africa Global Media, 2013; GHO, 2014).

\section{Study Purpose}

The purpose of this study was to examine the social and cultural determinants which impact self-care and health maintenance of the women of Swaziland. The goals related to this were to uncover cultural values, beliefs and attitudes that affect the health of Swazi women, and to develop a deeper understanding of how strongly embedded cultural values are a determinant of health outcomes.

\section{METHODS}

\section{Theoretical Approach: The Pen-3 Model}

The theoretical approach underlying this study is the Person-Extended Family-Neighborhood
(PEN-3) model developed by Airhihenbuwa in 1989 (Airhihenbuwa, 2004). PEN-3 assumes that health behaviors develop within a culture and that society will reinforce or resist these behaviors via ideological systems such as the family, religious structures or the government In the PEN-3 model (Figure 1), the effects of culture on behavior can be positive and promote health, create barriers to good health, or be existential, i.e. unique to the culture but neither helpful nor harmful.

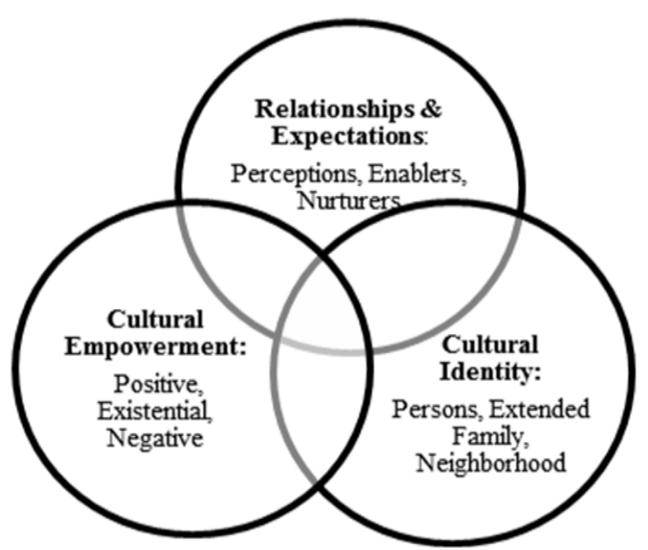

Figure1. The PEN-3 Model

This method of structuring highlights areas of strengths in a community as well as targets for intervention, and allows future health planning to be based on rational decisions that are also culturally sensitive.

\section{Research Participants}

Women were included in the study who were age 18-years or older, of Swazi heritage and had lived at least one full generation in Swaziland. Women had to be able to communicate verbally. Women did not have to speak English but they did have to be able to understand and answer questions and engage in conversations.

\section{Recruitment}

Participants for this qualitative study were selected through referral sampling from a community provider working in Swaziland. SZ does not have a formal research institutional review process; therefore, approval was granted by the university overseeing this study. This was approved as an exempt study. 


\section{Data Collection}

Data was collected initially from a focus group of eight women. Following the focus group, four women were invited to participate in individual interviews based on their interest, engagement and participation in the focus group. Participant incentives were food vouchers distributed following both the focus group and the home visits, and donated clothing. Each woman who participated in the focus group received a food voucher worth 120 emalangeni $(€)(\$ 10.23$ in US dollars). The women were also given time in a donated clothing room to select five clothing items per family member in the household. This ranged from 18-35 clothing items. The women who participated in the individual interviews and home visits received an additional incentive of a food voucher worth $€ 250$ (US \$21.75) at the completion of the interviews. The value of the food vouchers was based on the local economy and recommendations from the community provider.

Secondary data came from a variety of sources. These included observations of local practices and behaviors in public venues such as shops and markets; selected readings of local and national newspapers (The Times of Swaziland and The Swazi Observer); informal discussions with rural Swazi community leaders and individuals, and community providers; and, lengthy conversations held with the cultural interpreter who was a Swazi citizen. This data was recorded daily in detailed field notes.

\section{Interviews}

Interviews were conducted in English and translated from English into siSwati by the interpreter. Both the focus group and the individual interviews were audio-tape recorded and then transcribed for analysis. Use of a cultural interpreter fluent in both siSwati and English and familiar with local customs was invaluable. Table 1 provides a brief description of the study participants. Of the eight focus group members, four agreed to individual interviews and home visits (Gezephi, Nokthula, Siphiwe, and Alexia).
Table1. Focus Group Participants

\begin{tabular}{|l|l|l|l|}
\hline Participant & Age & Marital Status & $\begin{array}{l}\text { \# in } \\
\text { Household }\end{array}$ \\
\hline Nokthula & $\mathbf{2 8}$ & Widowed & 7 \\
\hline Siphiwe & 37 & Married/Single & 7 \\
\hline Monicah & $\mathbf{4 3}$ & Married & $\mathbf{5}$ \\
\hline Sibongile & $\mathbf{5 0}$ & Married & $\mathbf{6}$ \\
\hline Mary & $\mathbf{5 1}$ & Married & $\mathbf{8}$ \\
\hline Nomsa & $\mathbf{5 6}$ & Single & $\mathbf{4}$ \\
\hline Alexia & $\mathbf{6 7}$ & Widowed & $\mathbf{8}$ \\
\hline Gezephi & $\mathbf{8 3}$ & Widowed & $\mathbf{3}$ \\
\hline
\end{tabular}

\section{Data Analysis}

The methodological approach to data analysis in this study was based on critical ethnography (Carspecken, 1996), which incorporates narrative inquiry methods. The practice of analyzing data from a critical ethnographical perspective consists of five stages that are meant to be cyclical or recursive, rather than linear (see Table 2).

\section{Table2. Stages of Critical Ethnography}

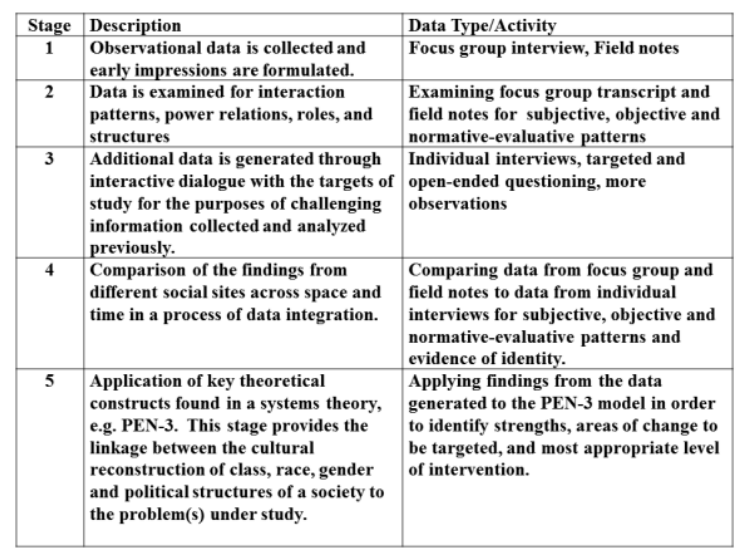

\section{Assumptions of the Methodology}

The methodology used in this study relies heavily on subjectivity and intersubjectivity. Qualitative research is designed to study the depth and breadth of an issue and to answer questions that investigate how and why certain phenomena of interest may be occurring (Maynes, Pierce \& Laslett, 2008; Riessman, 2008). To that end, this study has a small sample size and its findings are not intended to be 
generalizable to all women of Swaziland. The methodology used assumes that the participants have an ability to communicate underlying meaning through discourse (Carspecken, 1996). Three areas are at risk with the data analysis. One is that the relationship between the research participant and researcher was mediated by an interpreter due to a language barrier. Interpretation is a process that may have affected the meanings both sent and received. A second concern related to analysis is that the determination of meaning was carried out by a researcher from a culture outside of that of the research participants. Working towards an understanding of cultural norms by living within the culture helped to improve intersubjectivity. Lastly, it must be considered that the participants come from a country that has suffered oppression from a history of colonialism and race superiority. There was a perceived power differential from the outset of the study that was reinforced, albeit innocently, through using food and clothing items as research participation incentives.

\section{RESULTS}

Repeating themes found in the study included resource loss, employment difficulties, childhood education concerns, and mistrust of governmental agencies. Participants experienced a lack of basic resources that profoundly impacted their ability to feel safe and secure on a daily basis. Both food and housing insecurity were frequently cited concerns. These issues were related to a continued societal acceptance of the traditional roles of men and women in Swaziland despite changes in family structures and a breakdown in the multi-family homestead unit. The consequence of this was significant loss of both instrumental and emotional supports from: 1) husbands/fathers; and, 2) extended family networks. Following resource loss, employment opportunities for women were identified as a major concern. Women reported that they were unable to find work to support themselves or their families and the work that they did find was menial or required impractical travel and/or overnight stays. Several women also reported paying illegal bribes in order to find jobs, and then losing the money that they had paid when no jobs were forthcoming. Education for children repeatedly came up as a concern. The women in this study felt that a good education was a necessity for self-sufficiency, employment and improvement opportunities for their children, but they were unable to provide this without adequate resources. Health needs were a concern for women in this study, but only after other needs were addressed. Traditional medicine was viewed as generally ineffective and several of the women had experienced inadequate or harsh care in the existing medical system. Consequently, the women had developed a mistrust of formalized healthcare. Disease or losses in life were sometimes attributed to spiritual forces that were brought forth by the individual for seeking to break with tradition. Traditional roles and practices are strongly embedded in the Swazi culture and to behave in ways that are against custom was perceived as socially unacceptable and potentially dangerous to the individual and family. For example, one participant felt that her inability to have more than one child, his early demise, and her husband's death were all attributed to her refusal to become a witch doctor when called upon by her ancestors at an early age.

\section{Pen-3 Application}

The PEN-3 model (Table 3) is useful to highlight the areas identified in this study as having the most impact on women's health in Swaziland and to direct entry points for intervention.

\section{Table3. Pen-3 Application}

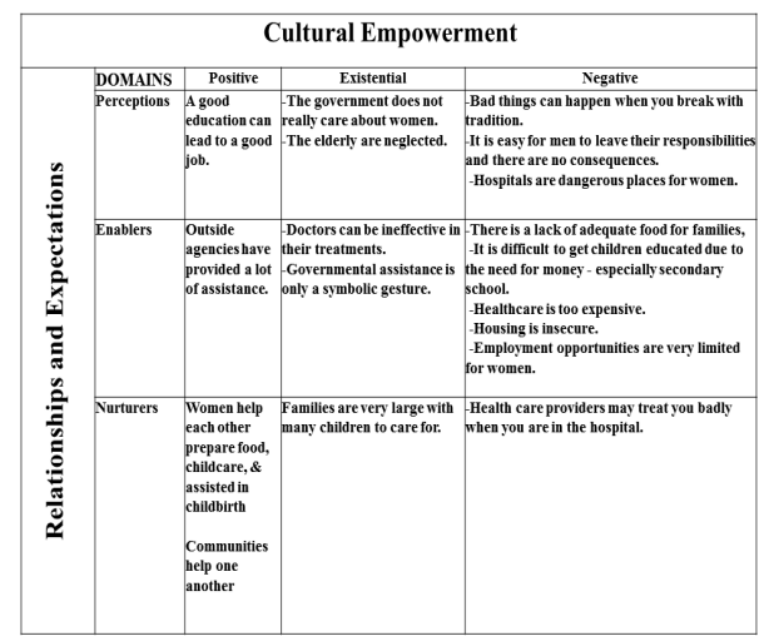




\section{Perceptions}

Women in the study believed that a good education could lead to a good job; therefore, education for their children was highly valued. Perceptions that were counterproductive to health included the belief that bad things could happen if you tried to break traditions, hospitals are dangerous places, and it is easy for men to leave their responsibilities.

\section{Enablers (Resources)}

Negative enablers (disablers) that worked against health maintenance included a lack of adequate nourishment, a lack of money for their children's education, a lack of money for healthcare, housing insecurity, and very limited employment opportunities. A positive enabler, or resource, found was that the participants have had previous good experiences in working with outside agencies. Identification of these resource needs and losses provide a roadmap specific to the types of public health targets that are identified as most important to the women in this study.

\section{Nurturers (Supports)}

This study suggests that extended family, community approaches and women-helpingwomen are culturally appropriate supports for this group.

\section{Cultural Identity}

Assessing cultural identity means evaluating the positioning of the person within her family and community, examining how a community's identity and capacity impact a health problem (Carspecken, 1996). Individual self-identity and identity claims play an integral role in placing the individual within their community. The women in this study were important key members of their family units. An age hierarchy was observable and the identity claims held by the women were shaped by their roles within their individual families. Overall, the community surrounding the women in this study was a loosely gathered grouping of individual homesteads that functioned independently with neighborly and external agency assistance.

\section{Mistrust of Healthcare Providers}

An intriguing finding was that the women in this study mistrusted hospitals and hospital nurses. This phenomenon has also been reported in a study of a small group of US nursing students who were observing nurses and nurse-midwives in a hospital maternity in SZ in 2014 (Murray, 2015). The students perceived that the nurses were not as empathetic as they expected them to be, and at times they behaved in a manner that was interpreted as aggressive towards the women in active labor. Similar attitudes towards nurses in SZ have been described by other authors (Klopper \& Uys, 2013). These reports are suggestive of a disabling cultural norm within the nurse-patient caring relationship and how nurses' perceive their role in terms of empathy.

An explanatory theory may be found in the work on oppression and horizontal violence by Freire and its subsequent application to the nursing profession by Roberts (Johnston, Phanhtharath \& Jackson, 2009). Freire theorized that oppression occurs within a group as a result of value suppression by a more dominant group. This results in feelings of inferiority and selfdoubt within the oppressed group. Roberts then applied this theory to the nursing profession, pointing out that nursing has traditionally been a group of women existing in a patriarchal world of male physicians. Nurses can display characteristics of oppressed groups, such as a sense of powerlessness and frustration. Nurses in SZ may be experiencing an intersectionality of oppressive identities which put them at high risk for enacting aggression on one another, and on other African women. This is problematic in that the women in this study did not feel safe in the hospital setting and they preferred home births, which puts both mother and child at greater risk for maternal and infant complications or mortality.

\section{DISCUSSION}

\section{The Impact of Changes in Family Structure}

The shift from an extended family and multifamily support network to individual and single parent households has had a great impact on the 
lives of women. With the advent of early death due to HIV/AIDS, tuberculosis, illness or accidents, Swazi families are changing rapidly. This is forcing a change in Swazi family systems: Middle-years women are becoming less available to care for their children, and grandmothers or even great-grandmothers are ending up with large numbers of young children to raise.

The Impact of Low Rates of Education and Employment

The educational and employment problems in Swaziland are large scale, systemic issues that should be examined at a national level. By continuing to invest federal monies in tertiary education disproportionate to secondary education, the government is ensuring that a high percentage of the poor remain undereducated: Only $18 \%$ of females and $21 \%$ of males currently complete 12-years of schooling (Central Statistical Office, 2008). For individuals without a secondary education, the jobs available to them are in the dwindling industrial, manufacturing and agricultural areas. These contributes to an unending cycle of poverty and internal oppression.

\section{Public Health Interventions}

Public health interventions should focus on the problems identified by the women: food, education, child assistance, safe housing, and health care access. According to PEN-3, the appropriate level of entry is the community. A possibility would be to develop an outreach program at a central location in collaboration with a community partner (e.g. church, school) and to work with local women who have leadership abilities. Ideas include self-sustaining programs such as a cooperative community garden where women with children can work in exchange for food, a sewing program to make school uniforms, or an arts/crafts program to raise money for a child education fund. Bringing in a local chapter of the existing advocacy group Women's Resource Center (Umtapo wa Bomake) may provide resources for long-term sustainability and support. Lastly, universities and non-governmental organizations can help with soliciting volunteers for community based health clinics and training local providers.

\section{CONCLUSION}

Swaziland is a small nation with a rich cultural heritage. Swazi's are proud of their country and its independence; yet, they struggle with internal challenges. Employment opportunities have dwindled over time and often both men and women in SZ must travel for work, which places stress on the family. Men may be gone for long periods or leave home and never return. Women are unable to find employment that allows them to care for their children and elderly parents, or to divorce and remarry when abandoned. As jobs have become more difficult to find and travel has increased, HIV/AIDS infection rates have also spread. This has led to further family system disruptions affecting women. Money is scarce for basic needs such as food, safe housing, and education. The women in this study did not feel that they were receiving much assistance from expected sources(men, extended family, or the Swazi government) and they had turned to neighbors and outside agencies for help. Participants also had a dislike of hospitals and the healthcare system due to previous experiences of ineffective or harsh treatment.

\section{ACKNOWLEDGEMENT}

A special "Thank you" to the organization, Saving Orphans through Healthcare and Outreach (SOHO), without whom this study could not have been completed. Their diligent work with families and child-headed households and their dedication to reducing violence against women and children through collaboration with Swaziland Action Group Against Abuse (SWAGAA) is to be applauded.

\section{REFERENCES}

[1] All Africa Global Media (2013, Oct. 18). Press Release. [Online]. MISA-Swaziland. Available: http://allafrica.com/stories/201310212089.html

[2] Airhihenbuwa, C. O. W., J.D., 2004, Culture and African contexts of HIV/AIDS prevention, care and support., Journal of Social Aspects of HIV/AIDS Research Alliance, 1(1), 4-13. 
[3] Bhalla, R.S., "Social stability through domestic relations: A critique of Swaziland's Marriage Act 1964”. In Forster, P.G. \& Nsibande, B.J. (Eds.), Swaziland: Contemporary social and economic issues, 2000, Burlington, VT: Ashgate Publishing Co.

[4] Carspecken, P.F., "Critical ethnography in educational research: A theoretical and practical guide". New York, NY: Routledge, 1996

[5] Central Statistical Office (CSO). Swaziland demographic and health survey 2006-07. Calverton, MA USA: Macro International, Inc., 2008

[6] Connolly, C. and Dunn, L.H., "Development of appropriate methods for sustaining rural health motivators: An operations research approach". Research paper no. 20. University of Swaziland. Kwaluseni, Swaziland: Social Science Research Unit, 1986.

[7] Fustos, K., "Gender-based violence increases risk of HIV/AIDS for women in sub-Saharan Africa" [Press release]. 2011, Online]Available: http://www.prb.org/Publications/Articles/2011/g ender-based-violence-hiv.aspx

[8] Gardsbane, D. \& Hlatshwayo, S., "Swaziland action group against abuse: Addressing genderbased violence within the context of HIV." US President's emergency plan for AIDS relief. AIDS Support and Technical Assistance (AIDSTAR-One) Project, Sector I, Task order 1: USAID Contract, 2012

[9] Global Health Observatory of the World Health Organization (GHO). Swaziland statistics summary (2002 - present), 2012, [Online]. Available: http://apps.who.int/gho/data/node. country.country-SWZ?lang=en

[10] Johnston, M., Phanhtharath, P., \& Jackson, B.S., 2009, The bullying aspect of workplace violence in nursing. Critical Care Nurse Quarterly, (32) 4, 287-295.

[11] Klopper, H.C. \& Uys., L.R., "Swaziland. The State of Nursing and Nursing Education in Africa: A country-by-country review". Indianapolis, IN: Sigma Theta Tau International, 2013
[12] Matsebula, J. S. M. A history of Swaziland (3 ${ }^{\text {rd }}$ ed.). Capetown, S.A: Longman Penguin Southern Africa (PTY) Ltd, 1988

[13] Maynes, M. J., Pierce, Jennifer L., and Laslett, B., Telling stories: The use of personal narratives in the social sciences and history. Ithaca, NY: Cornell University Press, 2008

[14] Ministry of Health, "Essential health care package for Swaziland. Swaziland: World Health Organization”, 2010, [Online] Available: http://www.mindbank.info/item/2792

[15] Murray, B., 2015, Nursing students' experiences of healthcare in Swaziland: Transformational processes in developing cultural understanding. Journal of Nursing Education, 54(9). September Supplement. S65-S73. doi: 10.3928/0148483420150814-13

[16] Riessman, C. K., Narrative methods for the human sciences. Thousand Oaks, CA: Sage Publications, 2008

[17] The Government of the Kingdom of Swaziland, (2014, June 4). [Online]. Available: http://www. gov.sz/index.php?option=com_content $\&$ view $=\mathrm{a}$ rticle\&id=170\&Itemid=209

[18] World Health Organization (WHO), "WHO African region: Swaziland statistics summary 2002-present"., 2002 [Online]. Available: http://www. who.int/countries.swz/en/

\section{AUTHOR'S BIOGRAPHY}

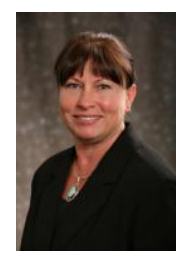

Bethany Murray, is an Academic Specialist with the Indiana University School of Medicine, and a practicing Clinical Nurse Specialist in child psychiatry. She completed her public health dissertation work in The Kingdom of Swaziland, Africa and currently works in rural Indiana in the United States.

Citation: Bethany A., Murray, PhD, RN. "Social and Cultural Factors in Women'S Health In Rural Africa." International Journal of Research in Humanities and Social Studies, vol 4, no. 5, 2017, pp. 17-23.

Copyright: (C) Bethany A., Murray, PhD, RN. This is an open-access article distributed under the terms of the Creative Commons Attribution License, which permits unrestricted use, distribution, and reproduction in any medium, provided the original author and source are credited. 